\section{Tai Chi for Preventing Recur- rence of Low Back Pain in Healthcare Workers}

\section{Mark J Bauernfeind ${ }^{1}, \mathrm{~K}$ Rao Poduri ${ }^{1 *}$ and Annemarie Groth-Juncker ${ }^{2}$}

${ }^{1}$ Department of Physical Medicine and Rehabilitation, University of Rochester Medical Center School of Medicine and Dentistry, Newyork, USA

${ }^{2}$ Department of Geriatric Medicine, University of Rochester Medical Center, Rochester, Newyork, USA

\section{Introduction}

Work-related Low Back Pain (LBP) is estimated to occur in approximately $5 \%$ of industry workers each year, resulting in the loss of 100 million work days and 9 billion dollars annually in the United States [1,2]. Approximately $34 \%$ of people who experience acute LBP will have recurrent episodes [3], with a resultant work disability rate of $17 \%$. Recurrences are typically more severe than the initial episode of LBP and have longer lengths of disability and higher associated healthcare costs [3]. LBP not only has physical, but also psychological consequences. For example, affected individuals may be unable to perform their jobs or may require modifications or restrictions in order to return to work. Further, untreated and/or inadequately managed acute pain can lead to chronic pain [4], further contributing to LBP-related morbidity. As a result of its substantial impact, LBP is considered to be a national health problem [5].

Healthcare workers, who are involved in direct patient care i.e., nursing professionals, have an increased risk for and a higher prevalence of LBP. According to one study, [6] working-life incidence rates and prevalence of LBP were $65 \%$ and $30 \%$ respectively for Orthopedic nurses. Activities such as turning and lifting patients and prolonged standing make this group particularly susceptible to work-related LBP and recurrent LBP.

Conventionally it is often claimed that up to $90 \%$ of LBP episodes spontaneously resolve within one month, despite the lack of strong and supporting evidence [7,8]. In addition, 80$90 \%$ of acute LBP cases are non-specific, without an identifiable structural pathology at the time of diagnosis, and the exact

${ }^{*}$ Corresponding author: Rao Poduri K, Department of Physical Medicine and Rehabilitation, University of Rochester Medical, Center School of Medicine and Dentistry, Newyork, USA, Tel: +1 5852753274; E-mail: KR_Poduri@URMC Rochester.edu

Citation: Bauernfeind M, Poduri KR, Groth-Juncker A (2016) Tai Chi for Preventing Recurrence of Low Back Pain in Healthcare Workers. J Phys Med Rehabil Disabil 2: 010.

Received: September 07, 2015; Accepted: March 14, 2016; Published: March 28, 2016 cause or mechanism of injury is not fully understood despite considerable research $[9,10]$. Further, the experience of pain is not only a result of physiologic factors, but it can also be due to cognitive, behavioral, socio-cultural, spiritual, and environmental factors. Thus treating acute and preventing recurrent LBP is complex.

Studies have demonstrated that chronic and/or recurrent LBP occurs significantly less frequently among patients who exercise regularly following the initial LBP treatment phase compared to those who are inactive [11]. Work absenteeism is also significantly lower among patients who are physically active. Stretching and strengthening exercises are linked to a reduction in disability and improved pain and functional outcomes [12-14]. Specifically, exercises which target the spinal stabilizing muscles, especially the lumbar multifidus group, have been found to significantly lower the risk of recurrent LBP [15-17]. In addition, when recurrent low back pain did occur, it was less severe than the initial injury. Exercise is a low-cost treatment option with too little to no side effects, but systematic reviews of the literature indicate a mixed view of its value [18-21].

Tai Chi is a form of exercise that is particularly well-suited for retraining and strengthening the lumbar stabilizing muscles. Tai Chi has been shown to relieve stress and to build self-confidence in patients affected with musculoskeletal diseases [22]. In addition, it contributes to cardiovascular health, improves balance, and decreases the number of falls [23]. As such, Tai Chi has been shown to be a potentially effective intervention for LBP. In this pilot study, we sought to determine whether Tai Chi could prevent the recurrence of LBP in a high risk group, specifically healthcare workers who provide direct patient care. A randomized controlled study by Hall et al., [24] including Paul Lam the inventor of "Tai Chi for back pain" as a co-author, studied the effects of Tai Chi on pain and disability in people with long-term LBP and was proven to be beneficial. Studying the effect of Tai Chi in healthcare workers is the unique aspect of our study.

\section{Methods}

Our prospective cohort pilot study involved healthcare workers with a history of LBP employed at either an acute inpatient nursing unit or at two skilled nursing facilities. The individuals included in this study were 8 hours a day shift workers who had no history of past illnesses. Announcements posted in nursing units and oral presentations on the study by the authors during nursing staff meetings were utilized to facilitate participant recruitment. The nursing directors from the three facilities provided letters of support and permission for their staff to participate in the study. Participants did not receive any compensation for this study. This study was approved by the University of Rochester Institutional Review Board.

Inclusion criteria were: age18 years or older; employment as a healthcare worker (RN, LPN, CNA, home health aide, PT, OT) in one of the participating sites; involved in direct patient care; and had one or more episodes of acute LBP within the last 5 years. Participants were ineligible to participate if one or more of the following applied: (a) no history of back pain ever, (b) currently on work restriction, (c) a history of LBP requiring medical treatment 3 months preceding 
Citation: Bauernfeind M, Poduri KR, Groth-Juncker A (2016) Tai Chi for Preventing Recurrence of Low Back Pain in Healthcare Workers. J Phys Med Rehabil Disabil 2: 010.

- Page 2 of 5 •

\begin{tabular}{|l|l|l|}
\hline \multicolumn{1}{|c|}{ Name } & \multicolumn{1}{c|}{ Description } & \multicolumn{1}{|c|}{ Use in Study } \\
\hline Roland-Morris Disability Questionnaire & $\begin{array}{l}\text { A 24-item health status measure which assesses physical } \\
\text { disability due to LBP. Participants check the statement that } \\
\text { applies to them. Checks are summed for a total score (0- } \\
24) \text {. Scores are measured serially for clinical improvements. }\end{array}$ & $\begin{array}{l}\text { The subjects' responses at baseline and three months } \\
\text { post Tai Chi training-practice were recorded. }\end{array}$ \\
\hline $\begin{array}{l}\text { The Oswestry Disability Index 2.0 for LBP/Dysfunc- } \\
\text { tion }\end{array}$ & $\begin{array}{l}\text { This 10-item measure, each with six response options, mea- } \\
\text { sures how impairing/disabling LBP is to the participant. }\end{array}$ & $\begin{array}{l}\text { Participants were asked to check the statement that } \\
\text { applies to them before the Tai Chi training and three } \\
\text { months post-intervention. }\end{array}$ \\
\hline SF36 Version 2 Questionnaire (for adults) & $\begin{array}{l}\text { Consists of eight equally weighted scales in two categories } \\
\text { 1. Physical Health (Physical Functioning, General Health, } \\
\text { Bodily Pain, and Role-Physica) 2. Mental Health: (Social } \\
\text { Functioning, Role-Emotional, Vitality, Mental Health) on a } \\
0-100 \text { scale; 50 is the average/norm. }\end{array}$ & $\begin{array}{l}\text { The subjects' responses at baseline and three months } \\
\text { post Tai Chi training-practice were recorded. }\end{array}$ \\
\hline
\end{tabular}

Table 1: Survey Measures.

enrollment in the study, (d) surgery in the lumbar region in the last 3 months, (e) epidural or facet joint injections received with the past 3 months, (f) non-musculoskeletal LBP or pelvic pain, and (g) recent injury to hips or knees as well as spinal or long bone fractures.

\section{Measures}

Prior to the Tai Chi intervention, participants filled out standard demographic background and general health history forms. They also completed three survey measures commonly used to assess back pain and health related quality of life pre-and post-intervention: 1) The Roland-Morris Disability Questionnaire for LBP [24], 2) the Oswestry Disability Index 2.0 (also known as Oswestry Low Back Pain Disability Questionnaire and considered "the gold standard" of low back functional outcome tools $[25,26]$ and 3) the SF36 version 2 questionnaire (a measure of quality of life) (Table 1) [27].

Participants were asked to complete a diary recording of how many times they practiced Tai Chi exercises prior to their work shift. They were also instructed to record any recurrences of LBP and any time lost from work as a result of LBP. After three months, all participants were asked to again complete the Roland-Morris Disability Questionnaire, the Oswestry Disability Index 2 and SF36 Version 2. Pre-and post-Tai Chi intervention responses were then compared. Our outcome measures were twofold: 1) primary outcome of recurrent LBP (defined as an incident of back pain during the study period), and 2) sick leave due to LBP.

\section{Intervention}

This study utilized specifically designed exercise routines based on Dr. Paul Lam's Tai Chi for Back Pain, which has not only been taught in the US and in other countries, but also has been approved by several Arthritis Foundations [23,28]. Dr. Lam's Tai Chi practice involves slow movements focusing on body posture. These movements include weight shifting, bending, extending the back, and twisting the trunk and largely involving the spinal stabilizing muscles. The roles of the muscles continually change between weight bearing and non-weight bearing phases and between contraction and relaxation, thus strengthening the inner stabilizing muscles as well as the external moving muscle groups. Deep abdominal breathing and full concentration while performing the movements are essential aspects of the practice and help relieve low back muscle pain as well as mental stress.

A certified Tai Chi instructor provided training in Dr. Paul Lam's Tai Chi for Back Pain [27] during two 45-minute sessions. At the end of the second session, participants were asked to demonstrate that they could perform the Tai Chi exercise routine independently. After completing the training, participants were instructed to perform the
Tai Chi for Back Pain routine for 5 to 7 minutes prior to every work shift. A Tai Chi teacher or instructional video were available if participants required additional practice and/or training.

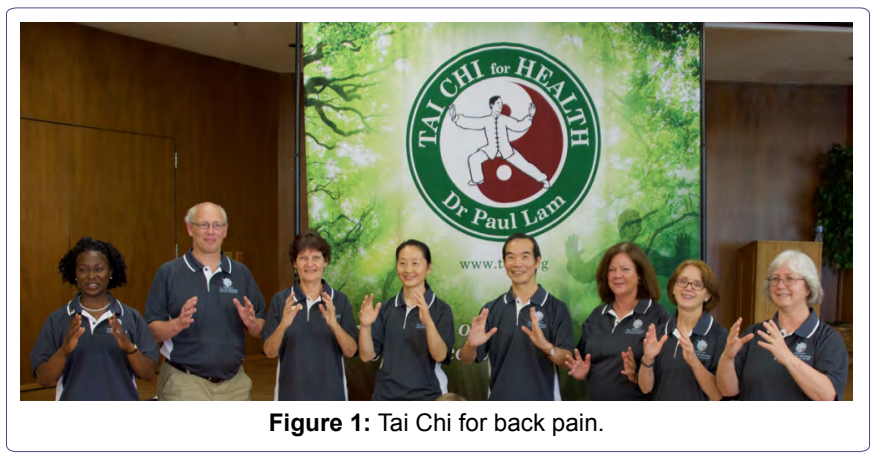

\section{Data Analyses}

At the end of the study participants were divided into two groups: (1) Those practiced Tai Chi (at least 3 times a week) and (2) those who did not practice Tai Chi or only practiced less than 3 times a week. The groups were further subdivided based on whether or not they experienced LBP during the study period, specifically noting recurrences of LBP and days lost from work as a result of LBP. Given our small sample size, we used the student's $\mathrm{t}$-test to analyze group differences in questionnaire responses among participants who practiced Tai Chi and those who did not.

To summarize, participants were taught an exercise routine based on Tai Chi for Back Pain, maintained a diary of the frequency of their Tai Chi practice, and noted any recurrence of LBP or days of work lost due to back pain. Each participant completed pre-and post-intervention survey measures consisting of the Roland-Morris Disability Questionnaire, the Oswestry Disability Index 2, and the SF36 Version 2 questionnaires. Pre- and post-intervention data were then analyzed in the Tai Chi practicing group and compared with data from the non- Tai Chi practicing group.

\section{Results}

Thirty healthcare workers consented to participate in the study. Of the 30, 20 completed the study and 10 were excluded from data analyses because they did not complete either the follow-up questionnaires or the training. Study participants included 20 healthcare workers (18 females, 2 males) with a history of LBP who worked directly with patients at either an acute inpatient nursing unit or at a skilled nursing facility. The mean age of participants was 45.5 years (range 25-60) with an average work history of 19 years (range 2-40). Participants included 11 nursing staff, 5 nursing aides, 
Citation: Bauernfeind M, Poduri KR, Groth-Juncker A (2016) Tai Chi for Preventing Recurrence of Low Back Pain in Healthcare Workers. J Phys Med Rehabil Disabil 2: 010.

- Page 3 of 5 •

\begin{tabular}{|c|c|c|c|c|c|c|c|c|}
\hline \multirow{2}{*}{$\begin{array}{c}\text { Subject } \\
\text { Pain } \\
\end{array}$} & \multirow[t]{2}{*}{ Roland Morris Pre ${ }^{1 *}$} & \multirow[t]{2}{*}{ Roland Morris Post ${ }^{1 *}$} & \multirow[t]{2}{*}{ Oswestry Pre ${ }^{2 *}$} & \multirow[t]{2}{*}{$\begin{array}{c}\text { Oswestry } \\
\text { Post }^{2 *}\end{array}$} & \multicolumn{2}{|c|}{$\begin{array}{l}\text { SF-36 } \\
\text { Pre }^{3}\end{array}$} & \multicolumn{2}{|c|}{$\begin{array}{l}\text { SF-36 } \\
\text { Post }^{3}\end{array}$} \\
\hline & & & & & PC & MC & PC & MC \\
\hline A & 5 & 2 & $34 \%$ & $46 \%$ & 30.0 & 37.1 & 32.1 & 37.3 \\
\hline B & 2 & 0 & $24 \%$ & 0 & 52.3 & 58.2 & 51.1 & 58.6 \\
\hline C & 1 & 0 & $12 \%$ & 0 & 54.8 & 52.1 & 56.7 & 52.2 \\
\hline \multicolumn{9}{|l|}{ No Pain } \\
\hline $\mathrm{D}$ & 3 & 1 & $26 \%$ & $6 \%$ & 46.7 & 53.8 & 58.7 & 43.3 \\
\hline E & 0 & 0 & $0 \%$ & 0 & 60.0 & 56.0 & 59.1 & 55.3 \\
\hline $\mathrm{F}$ & 0 & 0 & $8 \%$ & 0 & 58.5 & 42.2 & 56.5 & 48.9 \\
\hline G & 0 & 0 & $0 \%$ & 0 & 59.6 & 52.6 & 60.5 & 65.2 \\
\hline $\mathrm{H}$ & 5 & 4 & $26 \%$ & $46 \%$ & 48.6 & 60.8 & 54.7 & 54.8 \\
\hline 1 & 4 & 0 & $18 \%$ & $13 \%$ & 51.1 & 56.9 & 53.6 & 51.6 \\
\hline $\mathrm{J}$ & 3 & 2 & $40 \%$ & $12 \%$ & 45.1 & 61.9 & 57.8 & 57.6 \\
\hline
\end{tabular}

Table 2: Pre- and Post Scores of those Participants who Practiced Tai Chi.

${ }^{1}$ Scores are on a scale of 1-24

${ }^{2}$ Obtained score/total possible score $\mathrm{x} 100$

${ }^{3}$ Norm-based scores for Physical Component (PC) and Mental Component (MC)

${ }^{*}$ Significant decrease from pre- to post-study $(p<0.00001)$

\begin{tabular}{|c|c|c|c|c|c|c|c|c|}
\hline Subject & Roland Morris Pre ${ }^{1}$ & Roland Morris Post ${ }^{1}$ & Oswestry $\mathrm{Pre}^{2}$ & Oswestry Post ${ }^{2}$ & \multicolumn{2}{|c|}{ SF-36 Pre $^{3}$} & \multicolumn{2}{|c|}{ SF-36 Post ${ }^{3}$} \\
\hline \multicolumn{5}{|l|}{ Pain } & PC & MC & PC & MC \\
\hline $\mathrm{K}$ & 0 & 2 & $8 \%$ & $30 \%$ & 51.8 & 43.5 & 49.9 & 42.8 \\
\hline $\mathrm{L}$ & 4 & 3 & $10 \%$ & $14 \%$ & 39.6 & 48 & 33.3 & 53.6 \\
\hline M & 7 & 7 & $30 \%$ & $44 \%$ & 51.4 & 42.8 & 42.1 & 38.1 \\
\hline $\mathrm{N}$ & 0 & 0 & $22 \%$ & $25.4 \%$ & 44.7 & 55.4 & 25.3 & 60.9 \\
\hline 0 & 0 & 5 & $10 \%$ & $6 \%$ & 55.1 & 37.7 & 54.6 & 56.2 \\
\hline \multicolumn{9}{|l|}{ No Pain } \\
\hline $\mathrm{P}$ & 0 & 0 & 0 & 0 & 60 & 56 & 59.1 & 55.3 \\
\hline Q & 2 & 0 & 0 & 0 & 48.1 & 51.4 & 42.9 & 46.6 \\
\hline $\mathrm{R}$ & 4 & 0 & $20 \%$ & $2 \%$ & 48.1 & 52.6 & 56 & 47.1 \\
\hline $\mathrm{s}$ & 0 & 0 & 0 & 0 & 58.5 & 56.6 & 60.8 & 49.6 \\
\hline T & 0 & 0 & 0 & 0 & 59.6 & 52.6 & 60.5 & 65.2 \\
\hline
\end{tabular}

Table 3: Pre and Post Study Scores for those Participants who did NOT practice Tai Chi or Only practiced sometimes.

${ }^{1}$ Scores are on a scale of 1-24

${ }^{2}$ Obtained score / total possible score $\times 100$

${ }^{3}$ Norm-based scores for Physical Component (PC) and Mental Component (MC)

3 occupational therapists and 1 physical therapy aide. All participants had a history of LBP for less than 11 years. LBP history was self-reported in all but one participant, who had a confirmed diagnosis of LBP and had previously undergone surgery. None of the participants had physical therapy for the back pain. Twelve participants were taking Non-Steroidal Anti-Inflammatory Drugs (NSAIDs) rarely on an as-needed basis.

At 3-month follow-up, while none of the subjects reported loss of work due to LBP, eight reported back pain during the study. None of the study subjects experienced adverse effects related to Tai Chi. Ten of the $20(50 \%)$ subjects reported practicing most days, 3 sometimes (less than 3 times a week) and 7 did not practice at all. Twelve of the $20(60 \%)$ considered the Tai Chi routine easy to practice and $6(30 \%)$ found it difficult. The main reason provided for not practicing was lack of time. In addition, two participants stated they had trouble understanding the technique (never utilizing the video provided or asking the instructor during the study).

Of the 10 participants who practiced most days, three (30\%) reported LBP during the study period. Of the seven that did not practice, five (71\%) reported LBP. Major findings are summarized in tables 2 and 3. A comparison of the scores for those who regularly practiced Tai Chi on the Roland Morris Disability Questionnaire (the average of the number of items checked describing the back pain) showed a significant decrease in scores from pre- to post-study $\left(\mathrm{p}<0.00001\right.$, mean of 1.4 , St. dev. of 1.35 , and a $t_{9}$ of -3.28$)$. Similarly, on the Oswestry Disability Index 2.0 which quantifies disability from back pain the pre- to post-study scores for 6 subjects significantly decreased $(\mathrm{p}<0.00001)$ with a mean of -0.1617 , St. dev. $=0.0922$, and $t_{5}=-4.30$. On the SF-36 Version 2 which is a health survey that asks 36 questions to measure functional health and well-being as a 
measure of physical and mental health, the pre-to post-study score differences were not significant on either physical or mental components.

\section{Discussion}

Low back pain often results in disability and, even when it does not; it can negatively impact quality of life. Its deleterious effects have been demonstrated in morbidity, immune function, sleep, cognition, nutrition, mobility, psychosocial behaviors, and overall functional status. In addition, chronic pain, which can result from LBP, is widely believed to represent its own disease entity and can cause long-term detrimental physiologic changes, resulting in unique treatment challenges.

As this study highlights, Tai Chi practice has the potential to reduce and even prevent recurrence of LBP in higher risk populations such as healthcare workers. As with many other exercise-based interventions, however, there are important confounding factors to consider that can affect patient adherence to and success with the Tai Chi routine. First, the efficacy of Tai Chi is largely determined by patient effort. Second, expectations of degree of pain relief influence participant motivation. Third, those who regularly practice Tai Chi are more likely to be mindful of behaviors that might cause LBP, and as a result may simultaneously change their habits, reducing their risk. Lastly, perceived feelings of control over pain can lead to decreased fear of exercising, continued exercise, and ultimately reduced pain perception. While no prior similar studies exist in healthcare workers, extrapolations can be made from studies with other occupational groups. For instance, in one study of 1068 workers who submitted Workers' Compensation claims for back pain, low recovery expectations and fear that work may increase pain or cause further harm were found to be risk factors for chronic disability [29]. Another study reported that pain-related fear of movement or fear of causing further harm slows recovery and increases risk of developing chronic pain [30]. Although they are subjective and hard to quantify, it is important that future studies include measures of psychological factors, which significantly contribute to pain tolerance and treatment efficacy. Examples of these psychological factors include the expectations regarding pain, patient self-assessment of general wellbeing, and motivation to participate in study interventions when assessing treatment efficacy $[8,31]$.

While the number of participants in our study is small, the magnitude of LBP as a physical, psychological, and societal disease process with associated significant morbidity. Therefore it warrants further research involving a larger number of high risk participants, such as healthcare workers, from multiple sites and should address psychosocial factors. This will be essential to confirming these findings and determining the potential of Tai Chi to reduce LBP recurrence in healthcare workers. Tai Chi practice could potentially be a low-cost treatment modality for this high-risk population, augmenting the already available approaches that include narcotics, physical therapy, surgery, NSAIDs, and exercise [32].

Future Randomized Controlled Trials (RCTs) are needed to provide further evidence of Tai Chi's beneficial effect on low back strengthening, injury prevention, and alleviation of pain for healthcare workers. While various methodological approaches have been developed to identify LBP recurrences, including that by Deyo et al., [33], there exists no standardized definition of recurrence of LBP or required follow-up time [34].

\section{Conclusion}

This pilot trial of 20 healthcare workers showed that a specific exercise program, Tai Chi for Back Pain, significantly $(\mathrm{p}<0.00001)$ reduced the recurrence of LBP in this population using pre- and post-exercise scores derived from the Roland Morris Disability Questionnaire and the Oswestry Disability Index 2.0. While prior studies have examined the effects of Tai Chi on pain and disability in people with long-term LBP, our study for the first time focused specifically on healthcare workers. Even though this study brings to light the difficulties of researching exercise-based interventions, it also demonstrates that Tai Chi practice has the potential to reduce and even prevent recurrence of LBP. This study therefore emphasizes, the need for further research into Tai Chi's role in LBP treatment and prevention.

\section{References}

1. Pransky G, Benjamin K, Hill-Fotouhi C, Fletcher KE, Himmelstein J, et al (2002) Work-related outcomes in occupational low back pain: a multidimensional analysis. Spine (Phila Pa 1976) 27: 864-870.

2. Wheeler AH (2006) Pathophysiology of Chronic Back Pain. W-medicine.

3. Wasiak R, Kim J, Pransky G (2006) Work disability and costs caused by recurrence of low back pain: longer and more costly than in first episodes. Spine (Phila Pa 1976) 31: 219-225.

4. Walker BF (2000) The prevalence of low back pain: a systematic review of the literature from 1966 to 1998. J Spinal Disord 13: 205-217.

5. Deyo RA, Cherkin D, Conrad D, Volinn E (1991) Cost, controversy, crisis: low back pain and the health of the public. Annu Rev Public Health 12: 141-156.

6. Vieira ER (2007) Why Do Nurses Have a High Incidence of Low Back Disorders, and What Can Be Done to Reduce Their Risk? Bariatric Nursing and Surgical Patient Care 2: 141-148.

7. Hestbaek L, Leboeuf-Yde C, Manniche C (2003) Low back pain: what is the long-term course? A review of studies of general patient populations. Eur Spine J 12: 149-165.

8. Hincapié CA, Cassidy JD, Côté P (2008) Is a history of work-related low back injury associated with prevalent low back pain and depression in the general population? BMC Musculoskelet Disord 9: 22.

9. Frank JW, Kerr MS, Brooker AS, DeMaio SE, Maetzel A, et al. (1996) Disability resulting from occupational low back pain. Part I: What do we know about primary prevention? A review of the scientific evidence on prevention before disability begins. Spine (Phila Pa 1976) 21: 2908-2917.

10. Oleske DM, Lavender SA, Andersson GB, Morrissey MJ, Zold-Kilbourn P, et al. (2006) Risk factors for recurrent episodes of work-related low back disorders in an industrial population. Spine (Phila Pa 1976) 31: 789-798.

11. Taimela S, Diederich C, Hubsch M, Heinricy M (2000) The role of physical exercise and inactivity in pain recurrence and absenteeism from work after active outpatient rehabilitation for recurrent or chronic low back pain: a follow-up study. Spine (Phila Pa 1976) 25: 1809-1816

12. Kankaanpää M, Taimela S, Airaksinen O, Hänninen O (1999) The efficacy of active rehabilitation in chronic low back pain. Effect on pain intensity, self-experienced disability, and lumbar fatigability. Spine (Phila Pa 1976) 24: 1034-1042.

13. Frost H, Klaber Moffett JA, Moser JS, Fairbank JC (1995) Randomised controlled trial for evaluation of fitness programme for patients with chronic low back pain. BMJ 310: 151-154.

14. Mannion AF, Müntener M, Taimela S, Dvorak J (1999) A randomized clinical trial of three active therapies for chronic low back pain. Spine (Phila Pa 1976) 24: $2435-2448$. 
Citation: Bauernfeind M, Poduri KR, Groth-Juncker A (2016) Tai Chi for Preventing Recurrence of Low Back Pain in Healthcare Workers. J Phys Med Rehabil Disabil 2: 010.

- Page 5 of $5 \cdot$

15. Hides JA, Jull GA, Richardson CA (2001) Long-term effects of specific stabilizing exercises for first-episode low back pain. Spine (Phila Pa 1976) 26 243-248

16. Barker KL, Shamley DR, Jackson D (2004) Changes in the cross-sectiona area of multifidus and psoas in patients with unilateral back pain: the relationship to pain and disability. Spine (Phila Pa 1976) 29: 515-519.

17. Williams M, Solomonow M, Zhou BH, Baratta RV, Harris M (2000) Multifidus spasms elicited by prolonged lumbar flexion. Spine (Phila Pa 1976) 25: 2916 2924.

18. Hart $L$ (2006) Exercise therapy for nonspecific low-back pain: a meta-analysis. Clin J Sport Med 16: 189-190.

19. Hayden JA, van Tulder MW, Malmivaara AV, Koes BW (2005) Meta-analysis: exercise therapy for nonspecific low back pain. Ann Intern Med 142: 765-775.

20. Liddle SD, Gracey JH, Baxter GD (2007) Advice for the management of low back pain: a systematic review of randomised controlled trials. Man Ther 12 310-327.

21. Long A, Donelson R, Fung T (2004) Does it matter which exercise? A randomized control trial of exercise for low back pain. Spine (Phila Pa 1976) 29 : 2593-2602.

22. Li JX, Hong Y, Chan KM (2001) Tai chi: physiological characteristics and beneficial effects on health. Br J Sports Med 35: 148-156.

23. Song R, Lee EO, Lam P, Bae SC (2003) Effects of tai chi exercise on pain balance, muscle strength, and perceived difficulties in physical functioning in older women with osteoarthritis: a randomized clinical trial. J Rheumatol 30: 2039-2044.

24. Hall AM, Maher CG, Latimer J, Ferreira ML, Lam P (2009) A randomized controlled trial of tai chi for long-term low back pain (TAI CHI): study rationale, design, and methods. BMC Musculoskelet Disord 10: 55
25. Roland M, Fairbank J (2000) The Roland-Morris Disability Questionnaire and the Oswestry Disability Questionnaire. Spine (Phila Pa 1976) 25: 3115-3124.

26. Fairbank JC, Pynsent PB (2000) The Oswestry Disability Index. Spine (Phila Pa 1976) 25: 2940-2952.

27. Ware JE Jr (2000) SF-36 health survey update. Spine (Phila Pa 1976) 25 3130-3139.

28. Lam P, Stephenson A (2004) Tai Chi for Back Pain: Rationale and Available Evidence Supporting Tai Chi as a Complementary Treatment. Medical Paradigm 1: 3-10.

29. Turner JA, Franklin G, Fulton-Kehoe D, Sheppard L, Wickizer TM, et al. (2006) Worker recovery expectations and fear-avoidance predict work disability in a population-based workers' compensation back pain sample. Spine (Phila Pa 1976) 31: 682-689.

30. Swinkels-Meewisse IE, Roelofs J, Schouten EG, Verbeek AL, Oostendorp RA, et al. (2006) Fear of movement/(re)injury predicting chronic disabling low back pain: a prospective inception cohort study. Spine (Phila Pa 1976) 31: 658-664.

31. Hurwitz EL, Morgenstern H, Chiao C (2005) Effects of recreational physical activity and back exercises on low back pain and psychological distress: findings from the UCLA Low Back Pain Study. Am J Public Health 95: 1817-1824.

32. Fullen BM, Baxter GD, O'Donovan BG, Doody C, Daly L, et al. (2008) Doctors' attitudes and beliefs regarding acute low back pain management: A systematic review. Pain 136: 388-396.

33. Deyo RA, Battie M, Beurskens AJ, Bombardier C, Croft P, et al. (1998) Outcome measures for low back pain research. A proposal for standardized use. Spine (Phila Pa 1976) 23: 2003-2013.

34. Wasiak R, Pransky GS, Webster BS (2003) Methodological challenges in studying recurrence of low back pain. J Occup Rehabil 13: 21-31. 